\title{
ISOFLAVANS DERIVATIVES AS INHIBITORS OF SOYBEAN LIPOXYGENASE: IN-VITRO AND DOCKING STUDIES
}

\section{CAROLINA MASCAYANO ${ }^{*}$, MARCOS CAROLI REZENDE ${ }^{1}$, YENIFER RIVERA ${ }^{1}$ AND VICTORIA ESPINOSA ${ }^{2}$}

\author{
1) Facultad de Quimica y Biología, Universidad de Santiago, Chile \\ 2) Faculdad de Ciencias Médicas, Universidad de Santiago, Chile
}

(Received: May 9, 2011 - Accepted: September 7, 2011)

\begin{abstract}
The lipoxygenases (LOX) are a family of non-heme iron-containing dioxygenases which catalyze the stereospecific insertion of molecular oxygen into arachidonic acid, leading to hydroxy derivatives as end products. In this work, we studied the behavior of seven isoflavans on 15-soybean lipoxygenases (15sLOX), comparing them with the known inhibitors quercetin and 3, 4-dihydroxybenzoic acid. Four of the seven investigated isoflavans showed $\mathrm{IC}_{50}$ values smaller than $50 \mu \mathrm{M}$, being more potent than quercetin or 3,4-dihydroxybenzoic acid. Besides a catecholic pattern, the presence of an aromatic ring B seems to confer additional activity to these compounds, a result which was rationalized by docking studies of these isoflavanss into the enzyme binding site.
\end{abstract}

Keywords: Soybean Lipoxygenase, Isoflavans Inhibitors, $\mathrm{IC}_{50}$ Values, Docking.

\section{INTRODUCTION}

The lipoxygenases (LOX) are a family of non-heme iron-containing dioxygenases which catalyze the stereospecific insertion of molecular oxygen into arachidonic acid [1], are classified with respect to their positional specificity of arachidonic acid oxygenation and are referred to as 5-, 8-, 12- and 15 -LOX $[2,3]$. The biological properties of human lipoxygenases (hLOX) have been extensively studied due to their involvement in several diseases including bronchial asthma, allergic rhinitis, inflammatory, skin diseases, rheumatoid arthritis (5-hLOX) [4], cancer, osteoporosis and cardiovascular diseases prostatic cancer and asthma (15-hLOX) [5] and breast cancer and psoriasis (12-hLOX) [6, 7].

The search for new LOX inhibitors has led to the synthesis and evaluation of a series of 3-aryl-3,4-dihydro-2-H-1-benzopyran or isoflavans derivatives in our laboratories [8]. Some of these compounds were found to exhibit interesting activities as inhibitors of soybean lipoxygenase-1 (sLOX); their $\mathrm{IC}_{50}$ values were comparable with those of other good lipoxygenase inhibitors like caffeic or benzoic acid derivatives $[9,10]$. Is important to mention that 15 -soybean lipoxygenase (15-sLOX) may be used as a model for 15 -hLOX, due to their similarity in structures and mechanism [11]. In the present work, we assayed the activities of seven isoflavanss, by measuring their $\mathrm{IC}_{50}$ values as in vitro inhibitors of 15 -sLOX, and docked them into the active site of the enzyme, relating the obtained activities with structural features present in these molecules.

\section{MATERIALS AND METHODS}

Melting points were recorded on a capillary Microthermal instrument, and were not corrected. Kinetics was run with a diode-array Scinco S-3100 spectrophotometer. All starting materials were commercially available (Aldrich), with purity higher than 98\%, and were used without further purification. The enzyme 15-sLOX (15-lipoxygenase soybean-P1) was purchased from Cayman Chemical.

Isoflavans 1a-1d, 2, 3a and 3b were prepared following a procedure reported previously [8]: after a Houben-Hoesch reaction of the appropriate phenol with a benzyl cyanide and $\mathrm{HCl} / \mathrm{ZnCl}_{2}$ in dry ethyl ether, the resulting hydroxylketone was cyclized to the isoflavones using $\mathrm{MeSO}_{2} \mathrm{Cl} / \mathrm{DMF}$ in the presence of $\mathrm{BF}_{3} \cdot \mathrm{Et}_{2} \mathrm{O}$. Reduction of the obtained isoflavone through catalytic hydrogenation with $\mathrm{Pd} / \mathrm{C}(10 \%)$ in acetic acid formed the corresponding isoflavans. In this way, the following isoflavans were prepared: 1a, m.p. $101^{\circ} \mathrm{C}$, lit.[12] m.p. $102^{\circ} \mathrm{C} ; \mathbf{1 b}$, m.p. $162^{\circ} \mathrm{C}$, lit.[8] m.p. $162^{\circ} \mathrm{C}$; 1c, m.p. $163^{\circ} \mathrm{C}$, lit.[8] m.p. $164^{\circ} \mathrm{C}$; 1d, m.p. $153^{\circ} \mathrm{C}$, lit.[12] m.p. $153^{\circ} \mathrm{C}, 2$, m.p. $160^{\circ} \mathrm{C}$, lit.[12] m.p. $159^{\circ} \mathrm{C} ; 3$ a, mp. $130^{\circ} \mathrm{C}$, lit.[13] m.p. $131^{\circ} \mathrm{C} ; 3$ bb, m.p. $95^{\circ} \mathrm{C}$, lit.[8] m.p. $96^{\circ} \mathrm{C}$

Kinetics and $\mathrm{IC}_{50}$ assay

$\mathrm{IC}_{50}$ values for all compounds were obtained in buffer $25 \mathrm{mM}$ Hepes $(\mathrm{pH}$ 7.5) with $0.01 \%$ Triton X-100 for 15 -sLOX and arachidonic acid as substrate $(10 \mu \mathrm{M})$. Enzyme rates were determined by monitoring the formation of hydroperoxyeicosatetraenoic acid (HPETE) at $234 \mathrm{~nm}$ with a Scinco S-3100 spectrophotometer at $25 \pm 0.1{ }^{\circ} \mathrm{C}$. The inhibitors $(1 \mathrm{mg} / \mathrm{mL}$ in DMSO $)$ were added to the buffered substrate and the reaction was initiated by addition of the enzyme 15 -sLOX $(2 \mu \mathrm{L})$. Control rates were measured using the same volume of DMSO as the volume of inhibitor. The $\mathrm{IC}_{50}$ value was determined by measuring the enzymatic rate at a variety of inhibitor concentrations (depending on the inhibitor potency) and plotting their percent inhibition versus inhibitor concentration. The data were fitted to a simple saturation curve using Graphpad Prisma 5.0 software [14], allowing the determination of the inhibitor concentration at $50 \%$ activity $\left(\mathrm{IC}_{50}\right)$.

Docking studies

All structures were built with the Gaussianview software [15]. Restrained electrostatic potential (RESP) charges were obtained at the B3LYP/6-31G** level of theory, employing the Gaussian 03 package [15]. Docking of inhibitors into the active site of the crystal structure of 15-lipoxygenase soybean-P1 (PDB code:1N8Q) at $2.1 \AA$ of resolution was performed with the AutoDock4 package [16], using a Lamarckian algorithm and assuming total flexibility of the inhibitors and partial flexibility of the His residues coordinated to $\mathrm{Fe}^{+3}$ inside the binding site. The grid maps were made up of $60 \times 60 \times 60$ points, with a grid-point spacing of $0.375 \AA$. The AutoTors option was used to define the ligand torsions, and the docking results were then analysed by a ranked cluster analysis, resulting in conformations with the highest overall binding energy (most negative $-\Delta \mathrm{G}_{\text {binding }}$ value).

\section{RESULTS AND DISCUSSION}

The structures of the isoflavans derivatives $\mathbf{1}, \mathbf{2}$ and $\mathbf{3}$ investigated in the present work are given in Figure 1.<smiles>[R3]c1ccc(C2COc3c(cc([R])c(Br)c3Br)C2)cc1Br</smiles>

\begin{tabular}{|c|c|c|c|c|c|}
\hline Isoflavans & $\mathrm{R}_{6}$ & $\mathrm{R}_{7}$ & $\mathrm{R}_{8}$ & $\mathrm{R}_{3}{ }^{\prime}$ & $\mathrm{R}_{4}{ }^{\prime}$ \\
\hline $1 \mathrm{a}$ & $-\mathrm{OH}$ & $-\mathrm{OH}$ & - & - & - \\
\hline $1 \mathrm{~b}$ & $-\mathrm{OH}$ & $-\mathrm{OH}$ & - & \multicolumn{2}{|c|}{$-\mathrm{OCH}_{2} \mathrm{O}-$} \\
\hline $1 \mathrm{c}$ & $-\mathrm{OH}$ & $-\mathrm{OH}$ & - & $-\mathrm{CH}_{3}$ & - \\
\hline $1 d$ & $-\mathrm{OH}$ & $-\mathrm{OH}$ & - & $-\mathrm{OCH}_{3}$ & $-\mathrm{OCH}_{3}$ \\
\hline 2 & - & $-\mathrm{OH}$ & $-\mathrm{CH}_{3}$ & - & $-\mathrm{Cl}$ \\
\hline $3 a$ & - & $-\mathrm{OH}$ & $-\mathrm{OH}$ & - & - \\
\hline $3 b$ & - & $-\mathrm{OH}$ & $-\mathrm{OH}$ & $-\mathrm{CH}_{3}$ & - \\
\hline
\end{tabular}


<smiles>O=c1c(O)c(-c2ccc(O)c(O)c2)oc2cc(O)cc(O)c12</smiles>

4
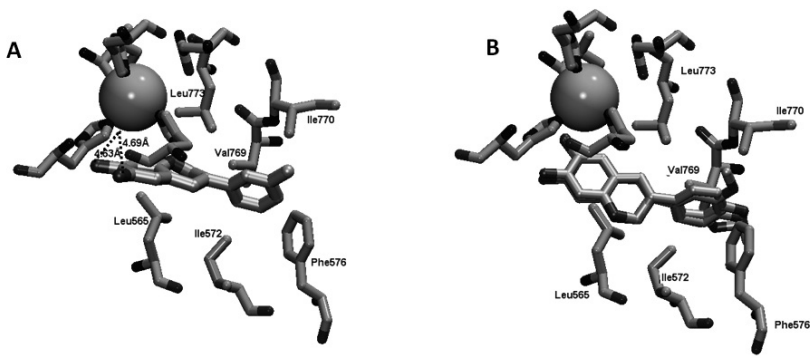

Figure 1: Structures of isoflavans derivatives 1, 2 and 3, quercetin 4 and 3,4-dihydroxybenzoic acid $\mathbf{5}$ used in the in vitro assays with 15 -sLOX and the docking studies.

Enzyme rates of formation of HPETE from arachidonic acid at $25^{\circ} \mathrm{C}$ in the presence of increasing concentrations of the isoflavans inhibitor yielded sigmoidal curves that allowed the determination of the corresponding $\mathrm{IC}_{50}$ values with errors smaller than $5 \%$. In order to validate our protocol and the obtained $\mathrm{IC}_{50}$ values, we first performed a control with quercetin $\mathbf{4}$ under the same conditions of our kinetics experiments. We obtained for this compond an $\mathrm{IC}_{50}$ value of $53 \mu \mathrm{M}$, very similar to the reported value of $50 \mu \mathrm{M}$ found in literature [17].The table 1 lists the $\mathrm{IC}_{50}$ values obtained for the seven isoflavans derivatives, for the sake of comparison, the corresponding values for quercetin $\mathbf{4}$ and for the 3,4-dihydroxybenzoic acid $\mathbf{5}$ are also given. Studies suggest that quercetin is presumably degraded to 3,4-dihydroxybenzoic acid [18], so that the latter was used in our docking studies as a compound reference for the investigation of the enzyme-inhibitor interactions, since a crystal structure of $\mathbf{5}$ bound to the 15-sLOX enzyme is also available (pdb code: 1N8Q) [18].

Table 1: $\mathrm{IC}_{50}$ values of 15-sLOX inhibitors 1-5.

\begin{tabular}{|c|c|}
\hline Isoflavans & $\mathrm{IC}_{50}(\mu \mathrm{M})$ \\
\hline $1 \mathrm{a}$ & $28 \pm 0.2$ \\
\hline $1 \mathrm{~b}$ & $26 \pm 0.1$ \\
\hline $1 \mathrm{c}$ & $18 \pm 0.1$ \\
\hline $1 \mathrm{~d}$ & $60 \pm 2.0$ \\
\hline 2 & $65 \pm 1.5$ \\
\hline $3 \mathrm{a}$ & $24 \pm 0.1$ \\
\hline $3 \mathrm{~b}$ & $90 \pm 1.5$ \\
\hline 4 & $53 \pm 2.0$ \\
\hline 5 & $74 *$ \\
\hline
\end{tabular}

*From reference [19]

Docking results showed that the most potent isoflavans $(\mathbf{1 a}, \mathbf{1 b}, \mathbf{1 c}$ and 3a) chelated the central iron atom through their catecholic hydroxyl groups, similarly to what was observed for 3,4-dihydroxybenzoic acid 5. For these inhibitors, the average distance between the catecholic oxygens and the iron atom was $5 \AA$, in good agreement with the distance obtained for compound $\mathbf{5}$ in the active site of the enzyme [18]. The fact that suppression of this catecholic pattern, as in compound $\mathbf{2}$, led to an increase of the $\mathrm{IC}_{50}$ value, suggests that this is an important structural feature for the inhibitory activity of these isoflavans.

Figure 2 shows isoflavans 1a-d bound to the same active site. All inhibitors are coordinated to the non-heme iron cation through the catecholic hydroxyl groups, a structural requirement that is emphasized in figure 2a. In addition, isoflavans 1a-d, through aromatic rings $\mathrm{C}$ and $\mathrm{B}$, may generate further interactions with hydrophobic fragments in the active site, such as $\mathrm{Leu}^{565}, \mathrm{Ile}^{572}$, $\mathrm{Phe}^{576}, \mathrm{Val}^{169}, \mathrm{Ile}^{770}$ and $\mathrm{Leu}^{773}$. Hydrophobic interactions with $\mathrm{Leu}^{565}$ and $\mathrm{Il}^{572}$ have been suggested to account for the activities of eugenol derivatives, as potent 15-sLOX inhibitors [20]. The insertion of the aromatic B ring of these inhibitors into a hydrophobic pocket formed by $\mathrm{Il}^{572}$, $\mathrm{Ile}^{770}$ and Val ${ }^{769}$ (Figure $2 b)$ may provide additional interactions between the isoflavans and the active site, thus strengthening its binding to the enzyme.

These two structural features may cooperate positively to the inhibitory activity of the isoflavans, as is the case with compounds $\mathbf{1 a}, \mathbf{1 b}, \mathbf{1} \mathbf{c}$ and $\mathbf{3 a}$ In the case of compounds $\mathbf{1 d}$ and $\mathbf{3 b}$, however, a decrease in their activity may be the result of opposing trends. Accomodation of the substituted ring B of these compounds into the hydrophobic pocket may require conformational adjustments that lead ultimately to a weaker interaction between the catecholic oxygens and the non-heme iron of the enzyme. The result is an $\mathrm{IC}_{50}$ value that approaches the value of the reference inhibitor 5

Figura2: (A) Coordination of 1c to the non-heme iron atom inside the binding site through its catecholic hydroxyl groups ; (B) Insertion of ring B of inhibitors $\mathbf{1 a}, \mathbf{1 b}$, and $\mathbf{1 d}$ superimposed into the hydrophobic pocket formed by $\mathrm{Ile}^{572}, \mathrm{Ile}^{770}$ and $\mathrm{Val}^{769}$.

In summary, the results showed an increased inhibitor activity of many of the isoflavans, when compared with quercetin 4 and 3, 4-dihydroxybenzoic acid $\mathbf{5}$, the docking studies revealed that the most active isoflavans were bound to the active site of the enzyme by coordination of their catecholic hydroxyl groups to the non-heme iron atom, reproducing the same behavior found in the crystalline structure of 5 bound to the enzyme [18]. The resulting inhibitory activity of these isoflavans would then be a compromise betweent these two factors, chelation of the central $\mathrm{Fe}^{+3}$ cation and accomodation of the substituted ring B within a hydrophobic pocket formed by Leu ${ }^{565}, \mathrm{Leu}^{773}, \mathrm{Val}^{769}, \mathrm{Ile}^{572}$ and $\mathrm{Il}^{\mathrm{7} 70}$ fragments.

\section{ACKNOWLEDGMENTS}

Financial support from DICYT-USACH project \# 021041MC is gratefully acknowledged

\section{REFERENCES}

1. S. Yamamoto, Biochim. Biophys. Acta. 1128, 117-131, (1992).

2. A.R. Brash, J. Biol. Chem. 274, 23679-23682, (1999).

3. H. Kuhn, B.J. Thiele, FEBS Lett. 449, 7-11, (1999).

4. J.Benites, J. Chil. Chem. Soc. 54, 379-384,(2009).

5. S. Chu, L. Tang, E. Watney, E.Y. Chi, W.R. Henderson, jimmunol. 165, 4640-4648, (2000).

6. K. Ikai, J. Dermatol. Sci. 21, 135-146, (1999).

7. V.E. Steele, C.A. Holmes, E.T. Hawk, L. Kopelovich, R.A. Lubet, J.A. Crowell, C.C. Sigman, G.J. Kelloff, cebp. 8, 467-483, (1999).

8. Y. Vasquez-Martinez, R.V. Ohri, V. Kenyon, T.R. Holman, S. SepúlvedaBoza, Bioorg. Med. Chem. 15, 7408-25, (2007).

9. Y. Koshihara, T. Neichi, S.I. Murota, A.N. Lao, Y. Fujimoto, T. Tatsuno, Biochim. Biophys. Acta. 792, 92-97, (1984).

10. W.R. Rusell, L. Scobbie. G.D. Duthie. A. Chesson. Bioorg Med Chem. 16, 4589-4593, (2008).

11. A.T. Wecksler, N.K. Garcia, T.R. Holman, Bioorg Med Chem. 17, 6534$6539,(2009)$.

12. A.I.Albert, F.W.Zilliken. Eur. Pat. Appl. EP 267155 A2 19880511, (1988).

13. H.Goto, Y.Terao, S.Akai, Chem.Pharm.Bull.57, 346-360, (2009).

14. GraphPad Software Inc., San Diego CA

15. Gaussian 09, Revision A.1, M. J. Frisch, G. W. Trucks, H. B. Schlegel, G. E. Scuseria, M. A. Robb, J. R. Cheeseman, G. Scalmani, V. Barone, B. Mennucci, G. A. Petersson, H. Nakatsuji, M. Caricato, X. Li, H. P. Hratchian, A. F. Izmaylov, J. Bloino, G. Zheng, J. L. Sonnenberg, M. Hada, M. Ehara, K. Toyota, R. Fukuda, J. Hasegawa, M. Ishida, T. Nakajima, Y. Honda, O. Kitao, H. Nakai, T. Vreven, J. A. Montgomery, Jr., J. E. Peralta, F. Ogliaro, M. Bearpark, J. J. Heyd, E. Brothers, K. N. Kudin, V. N. Staroverov, R. Kobayashi, J. Normand, K. Raghavachari, A. Rendell, J. C. Burant, S. S. Iyengar, J. Tomasi, M. Cossi, N. Rega, J. M. Millam, M. Klene, J. E. Knox, J. B. Cross, V. Bakken, C. Adamo, J. Jaramillo, R. Gomperts, R. E. Stratmann, O. Yazyev, A. J. Austin, R. Cammi, C. Pomelli, J. W. Ochterski, R. L. Martin, K. Morokuma, V. G. Zakrzewski, G. A. Voth, P. Salvador, J. J. Dannenberg, S. Dapprich, A. D. Daniels, Ö. Farkas, J. B. Foresman, J. V. Ortiz, J. CiosLOXwski, and D. J. Fox, Gaussian, Inc., Wallingford CT, 2009.

16. G.M. Morris, D.S. Goodsell, R.S. Halliday, R.Huey, W.E. Hart, R.K. Belew, A.J. Olson, J. Comput. Chem. 19, 1639-1662, (1998). 
17. S. Teklu, L.L. Gundersen, T. Larsen, K.E. Malterud, F. Rise, Bioorg Med Chem. 13, 3127-3139, (2005).

18. O.Y. Borbulevych, J. Jankun, S.H. Selman, E. Skrzypczak-Jankun, Proteins. 54,13-19, (2004).
19. C.L. Liu, J.M. Wang, C.Y. Chu, M.T. Cheng, T.H.Tseng, Food Chem. Toxicol. 40, 635-641, (2002).

20. H. Sadeghian, S. Seyedi, M. Saberi, Z. Aghiani, M. Riazi, Bioorg Med Chem. 16,890-901, (2008). 